\title{
Restoration of Lumbar Lordosis in Flat Back Deformity: Optimal Degree of Correction
}

\author{
Ki-Tack Kim ${ }^{1}$, Sang-Hun Lee ${ }^{1}$, Dae-Seok Huh ${ }^{2}$, Hyo-Jong Kim ${ }^{3}$, Jung-Youn Kim ${ }^{1}$, Jung-Hee Lee ${ }^{1}$ \\ ${ }^{1}$ Department of Orthopaedic Surgery, Kyung Hee University College of Medicine, Seoul, Korea \\ ${ }^{2}$ Department of Orthopaedic Surgery, CM Hospital, Seoul, Korea \\ ${ }^{3}$ Department of Orthopaedic Surgery, Shinsegye Hospital, Busan, Korea
}

\begin{abstract}
Study Design: A retrospective comparative study.
Purpose: To provide an ideal correction angle of lumbar lordosis (LL) in degenerative flat back deformity.

Overview of Literature: The degree of correction in degenerative flat back in relation to pelvic incidence (PI) remains controversial.

Methods: Forty-nine patients with flat back deformity who underwent corrective surgery were enrolled. Posterior-anterior-posterior sequential operation was performed. Mean age and mean follow-up period was 65.6 years and 24.2 months, respectively. We divided the patients into two groups based on immediate postoperative radiographs-optimal correction (OC) group $\left(\mathrm{PI}-9^{\circ} \leq \mathrm{LL}<\mathrm{PI}+9^{\circ}\right)$ and under-correction (UC) group ( $\left(\mathrm{LL}<\mathrm{PI}-9^{\circ}\right)$. We also classified the patients according to the PI of each patient-low PI group $\left(\mathrm{Pl}<55^{\circ}\right)$ and high Pl group $\left(\mathrm{Pl} \geq 55^{\circ}\right)$. Radiological and clinical results were analyzed.

Results: Patients in $\mathrm{OC}$ group had significantly less correction loss and maintained normal sagittal alignment (sagittal vertical axis $<5$ $\mathrm{cm})$, as compared to patients in UC group $(p<0.05)$. LL of low PI group significantly maintained within $9^{\circ}$ better than high $\mathrm{PI}$ group $(p<0.05)$. Oswestry disability index (ODI) significantly decreased at last follow-up, as compared to preoperative state. However, there was no significant difference in last follow-up ODI between the groups.

Conclusions: In flat back deformity, correction of $L \mathrm{~L}$ to within $9^{\circ}$ of PI will result in better sagittal balance. Thus, we recommend sufficient $\mathrm{LL}$ to prevent correction loss, especially in patients with high PI.
\end{abstract}

Keywords: Flat back deformity; Lumbar lordosis; Pelvic incidence

\section{Introduction}

'Flat back deformity' is a disorder of the thoracolumbar spine that results in chronic back pain and forward inclination of the trunk. The term 'flat back' was originally described by Doherty, as an iatrogenic complication of wherein thoracolumbar scoliosis correction by Harrington-distraction instrumentation [1]. Currently, it generally means sagittal imbalance caused by various factors [2]. Normal sagittal alignment is determined by various shapes and sizes of thoracic kyphosis (TK) and lumbar lordosis (LL) by the position of head, trunk, and pelvis in relation to the center of gravity. Loss of LL due to various causes usually initiates and leads to global sagittal imbalance. In flat back deformity, stooping of the trunk occurs because the lumbar spine, which is naturally lordotic, loses spinal sagittal balance by abnormal decrease in LL [3]. Conservative approach in flat back

Received Sep 6, 2014; Revised Nov 27, 2014; Accepted Nov 28, 2014

Corresponding author: Dae-Seok Huh

Department of Orthopaedic Surgery, CM Hospital,

13 Yeongdeungpo-ro 36-gil, Yeongdeungpo-gu, Seoul 150-034, Korea

Tel: +82-2-2678-0001, Fax: +82-2-2678-2175, E-mail: dae1016@hanmail.net 
Table 1. Patient demographics

\begin{tabular}{lccc}
$\begin{array}{l}\text { No. of patient } \\
\text { Age }(\mathrm{yr})\end{array}$ & Total $(\mathrm{n}=49)$ & $\begin{array}{c}\text { Optimal correction group } \\
(\mathrm{n}=35)\end{array}$ & $\begin{array}{c}\text { Under-correction group } \\
(\mathrm{n}=14)\end{array}$ \\
$\begin{array}{l}\text { Sex } \\
\text { Male }\end{array}$ & $65.6(55-76)$ & $65.2(55-76)$ & $06.6(56-73)$ \\
\hline Female & 4 & 4 & 14 \\
\hline Diagnoses & 45 & 31 & 9 \\
\hline Degenerative flat back & 24 & 15 & 4 \\
\hline latrogenic flat back & 10 & 6 & 1 \\
\hline Degenerative kyphoscoliosis & 15 & 14 & $26.2(12-61)$ \\
\hline Follow-up (mo) & $24.2(12-61)$ & $23.4(12-50)$ & 14 \\
\hline
\end{tabular}

deformity is inefficient and has uncertain effects. Therefore, it is important to restore abnormal LL to a normal balanced state by realignment surgical treatment $[4,5]$. There are various surgical approaches to treat flat back deformity, generally comprising the posterior only and the anterior and posterior combined approach $[6,7]$. Recent studies show that the anterior approach with interbody fusion at multiple levels combined with posterior reconstruction is effective in the restoration of LL, especially in lower lumbar levels [8]. After surgical correction of flat back deformity, LL can be well maintained throughout the follow-up period [9]. However, in some cases, correction loss may also occur during followup. Each individual has an inherent normal value of LL, which gradually decreases with age [10]. Thus, the target of surgery should focus on the restoration of LL to the original alignment. However, there is no definite criteria for the determination of the degree of restoration because each individual has a wide range of LL that varies from approximately $20^{\circ}$ to $60^{\circ}$. Pelvic incidence (PI) is one of the pelvic parameters that is an independent anatomical parameter and unique to individual. It determines pelvic orientation and size of LL. There have been numerous attempts to predict LL in relation to pelvic parameters [11-16]. Schwab et al. [15] suggested that LL should be within $9^{\circ}$ of PI for realignment of spinal deformity. The objective of this study was to provide an ideal correction angle of LL in degenerative flat back deformity based on the relationship between LL and PI from radiological and clinical results.

\section{Materials and Methods}

\section{Materials}

From January 2008 to December 2012, 61 patients with abnormal sagittal alignment underwent corrective surgery. The indications of correction were the 4 cardinal symptoms of degenerative flat back (stooping, difficulty in climbing, elbow support when washing dishes, and difficulty in holding in front of body) with intractable back pain or severe limitation to daily living activity, and radiographs showing global sagittal imbalance with sagittal vertical axis (SVA) $>8 \mathrm{~cm}$ [17]. Patients with $<1$ year follow-up and patients with post-traumatic kyphosis or degenerative scoliosis without kyphosis were excluded. Eventually, 49 patients ( 45 females and 4 males) were enrolled in the study (Table 1). Among them, 24 cases were pure degenerative flat back, 10 cases were iatrogenic flat back, and 15 cases were degenerative kyphoscoliosis. Mean age was 65.6 years (range, 55-76 years) and mean follow-up period was 24.2 months (range, 12-61 months). On the basis of the method by Schwab et al. [15], we categorized the patients into 2 groups based on immediate postoperative radiographs-optimal correction (OC) group (PI-9 $9^{\circ} \mathrm{LL}<\mathrm{PI}+9^{\circ}$ ) and under-correction (UC) group $\left(\mathrm{LL}<\mathrm{PI}-9^{\circ}\right)$. There were no patients with overcorrection. We also classified the patients according to the individual size of the PI-low PI group $\left(\mathrm{PI}<55^{\circ}\right)$ and high PI group $\left(\mathrm{PI} \geq 55^{\circ}\right)$. We selected $55^{\circ}$ as the reference point because the average PI among 61 patients was approximately $55^{\circ}$. Whole spine standing lateral view radiographs 
were taken preoperatively, immediate postoperatively, and at last follow-up in all patients.

\section{Surgical procedures}

All surgeries were performed by a single surgeon. Posterior-anterior-posterior sequential operation was conducted. From 2 to 4 levels of anterior lumbar interbody fusion (ALIF) was performed depending upon the case. The level of upper instrumented vertebra was from T8 to L2, which was determined by the sagittal angle of each individual. Distal fusion was carried out to the S1 and spinopelvic fixation using iliac screws in all cases. Additional osteotomy (pedicle subtraction osteotomy [PSO], 2; partial PSO, 9) was performed if sufficient LL was not achieved with the above method.

\section{Radiological analysis}

PI, TK, LL, and SVA were measured on 36-inch standing lateral radiographs of the entire spine at preoperative, postoperative, and follow-up examinations.

Cobb's angle between the upper end plate of $\mathrm{T} 5$ and the lower end plate of T12 was measured for TK, Cobb's angle between the upper end plate of L1 and the upper end plate of S1 was measured for LL. Kyphotic angle was expressed as a positive value, while lordotic angle was expressed as a negative value. For the SVA, a vertical distance was measured between the $\mathrm{C} 7$ plumb line and the posterosuperior corner of the S1 [18]. Positive and negative sagittal imbalance were defined by positive and negative values, respectively. All sagittal parameters were measured by 2 independent observers utilizing Picture Archiving and Communication System ( $\pi$ View, Infinitt, Seoul, Korea) (Fig. 1).

\section{Clinical analysis}

Oswestry disability index (ODI) [19] and visual analog scale (VAS) of low back pain were measured and compared before surgery and at the last follow-up. Medical records were evaluated for perioperative and postoperative complications.

\section{Statistical analysis}

The IBM SPSS ver. 21 (IBM Co., Armonk, NY, USA) was

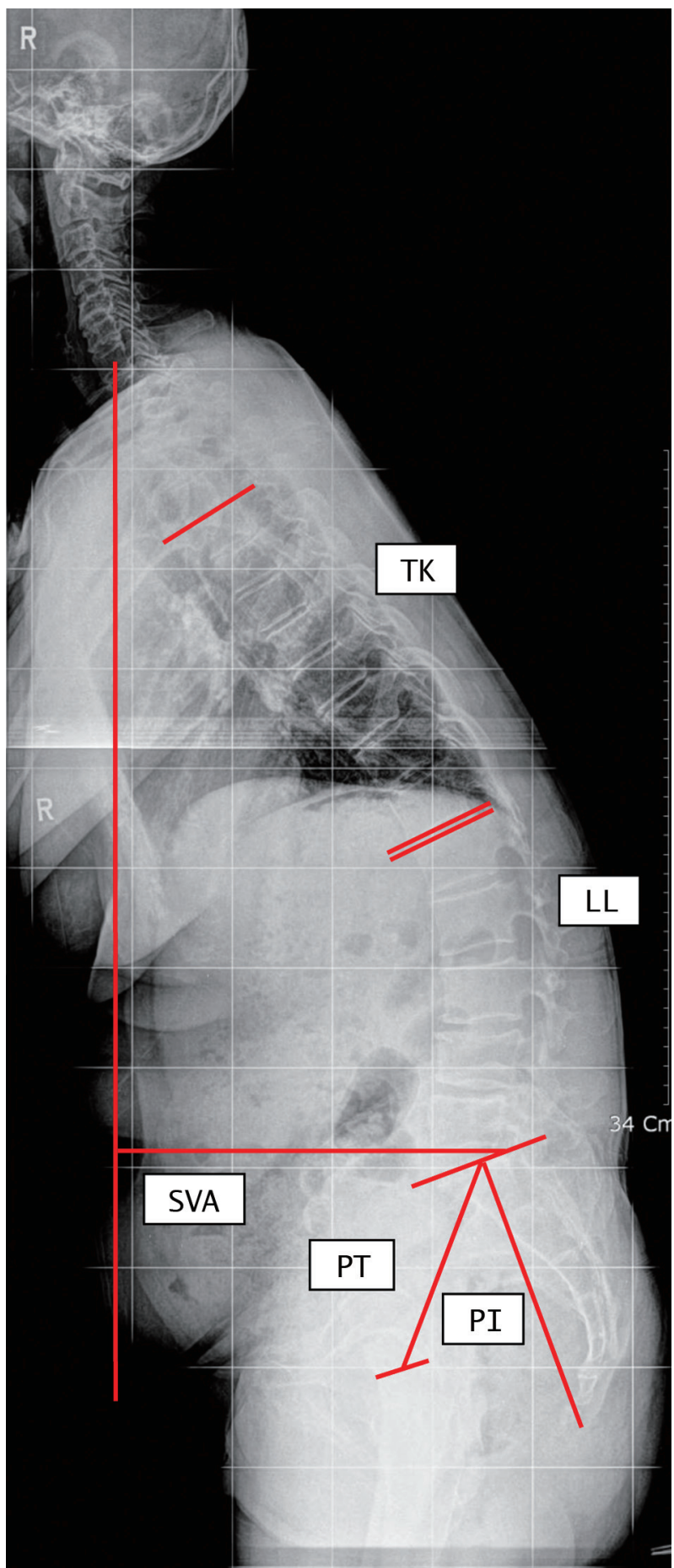

Fig. 1. Measurement of sagittal parameters. Sagittal vertical axis (SVA) was the distance between the C7 plumb line and the posterosuperior corner of S1. Thoracic kyphosis (TK) was the Cobb's angle between upper end plate of T5 and lower end plate of T12. Lumbar lordosis (LL) was the Cobb's angle between upper end plate of L1 and S1. Pelvic incidence (PI) was the angle between the perpendicular to the sacral plate at its midpoint and the line connecting this point to the middle axis of both femoral heads. Pelvic tilt (PT) was the angle between the line connecting the midpoint of the sacral plate to the axis of the femoral heads and the line perpendicular to the floor. 
Table 2. Radiologic results

\begin{tabular}{|c|c|c|c|c|c|}
\hline \multirow{2}{*}{ Parameters } & \multicolumn{3}{|c|}{ Average } & \multirow{2}{*}{ Range (total) } & \multirow{2}{*}{$p$-value ${ }^{\mathrm{a}}$} \\
\hline & Total & Optimal correction & Under-correction & & \\
\hline Pelvic incidence $\left({ }^{\circ}\right)$ & & & & & 0.165 \\
\hline Preoperative & $56.4 \pm 9.5$ & $54.6 \pm 9.5$ & $60.9 \pm 7.9$ & 32.6 to 76.2 & \\
\hline Postoperative & $53.0 \pm 8.7$ & $50.6 \pm 8.1$ & $60.6 \pm 5.4$ & 32.6 to 69.4 & \\
\hline Last follow-up & $56.5 \pm 8.9$ & $54.4 \pm 9.0$ & $62.9 \pm 7.4$ & 36.5 to 73.3 & \\
\hline Pelvic tilt $\left({ }^{\circ}\right)$ & & & & & 0.000 \\
\hline Preoperative & $36.8 \pm 9.0$ & $34.8 \pm 8.8$ & $41.5 \pm 7.9$ & 15.6 to 57.2 & \\
\hline Postoperative & $16.2 \pm 9.3$ & $12.5 \pm 7.6$ & $25.3 \pm 6.3$ & -5.2 to 37.1 & \\
\hline Last follow-up & $23.0 \pm 9.3$ & $21.2 \pm 6.6$ & $31.0 \pm 8.7$ & 4.9 to 45.4 & \\
\hline Thoracic kyphosis $\left({ }^{\circ}\right)$ & & & & & 0.000 \\
\hline Preoperative & $6.8 \pm 11.6$ & $7.7 \pm 12.3$ & $4.8 \pm 9.7$ & -21.3 to 46.1 & \\
\hline Postoperative & $22.7 \pm 10.5$ & $25.0 \pm 9.9$ & $17.0 \pm 10.0$ & 1.89 to 46.6 & \\
\hline Last follow-up & $33.0 \pm 11.3$ & $36.3 \pm 9.2$ & $24.2 \pm 11.6$ & -1.62 to 57.6 & \\
\hline Lumbar lordosis $\left({ }^{\circ}\right)$ & & & & & 0.000 \\
\hline Preoperative & $9.4 \pm 14.6$ & $7.1 \pm 15.1$ & $15.1 \pm 11.8$ & -14.9 to 48.1 & \\
\hline Postoperative & $-48.7 \pm 8.8$ & $-51.4 \pm 7.6$ & $-42.1 \pm 8.2$ & -67.3 to -26.7 & \\
\hline Last follow-up & $-47.2 \pm 12.0$ & $-50.5 \pm 8.9$ & $-38.4 \pm 14.5$ & -69.7 to -21.4 & \\
\hline Sagittal vertical axis (cm) & & & & & 0.000 \\
\hline Preoperative & $24.5 \pm 11.4$ & $22.4 \pm 10.7$ & $29.9 \pm 11.6$ & 6.8 to 50.3 & \\
\hline Postoperative & $2.1 \pm 3.9$ & $1.8 \pm 3.9$ & $2.9 \pm 3.8$ & -6.9 to 9.8 & \\
\hline Last follow-up & $4.2 \pm 4.1$ & $2.3 \pm 3.6$ & $6.0 \pm 4.1$ & -3.1 to 12.9 & \\
\hline
\end{tabular}

Values are presented as means \pm standard deviations.

${ }^{\text {a) }} \mathrm{p}$-value is comparison between preoperative and last follow-up data.

used for statistical analysis. Pearson's chi-square test were used to determine whether there were any significant differences among the 2 groups. A significance level of $95 \%$ was chosen and a $p$-value $<0.05$ was considered statistically significant.

\section{Results}

\section{Radiological results}

Preoperative/immediate postoperative/last follow-up PI was $56.4^{\circ} \pm 9.5^{\circ}, 53.4^{\circ} \pm 8.7^{\circ}$, and $56.8^{\circ} \pm 9.3^{\circ}$, respectively. PI was constant during the entire period $(p=0.165)$. Overall LL was $+9.4^{\circ}$ (range, $-14.9^{\circ}$ to $+48.1^{\circ}$ ) preoperatively, $-48.7^{\circ}$ (range, $-67.3^{\circ}$ to $-26.7^{\circ}$ ) postoperatively, and $-47.2^{\circ}$ (range, $-69.7^{\circ}$ to $-12.4^{\circ}$ ) at last follow-up. Overall preoperative pelvic tilt (PT) was $36.8^{\circ}$ (range, $15.6^{\circ}$ to $57.2^{\circ}$ ), which significantly decreased to $16.2^{\circ}$ (range, $-5.2^{\circ}$ to $37.1^{\circ}$ ) immediately after surgery and slightly increased to $23.0^{\circ}$ (range, $4.9^{\circ}$ to $45.4^{\circ}$ ) at the last follow-up. Overall SVA was $+24.5 \mathrm{~cm}$ (range, +6.8 to $+50.3 \mathrm{~cm}$ ) preoperatively, which significantly improved to normal range of $+2.1 \mathrm{~cm}$ (range, -6.9 to $+9.8 \mathrm{~cm}$ ) postoperatively, and $+4.2 \mathrm{~cm}$ (range, -3.1 to $+12.9 \mathrm{~cm}$ ) at the last follow-up. Based on SVA, 31 patients (63.3\%) had good maintenance $(\mathrm{SVA}<5 \mathrm{~cm})$ and 18 patients $(36.7 \%)$ has loss of correction $(\mathrm{SVA} \geq 5 \mathrm{~cm}$ ) at the last follow-up (Table 2).

Considering the adequacy of immediate postoperative correction angle of LL, 35 (71.4\%) of 49 patients were in OC group and 14 patients (28.6\%) were in UC group. Grouping according to size of PI, 22 patients were in low PI group $\left(\mathrm{PI}<55^{\circ}\right)$ and 27 patients were in high PI group $\left(\mathrm{PI} \geq 55^{\circ}\right)$. In low PI group, 19 out of 22 patients (86.4\%) were included in OC group, whereas in high PI group, only 16 out of 27 patients (59.3\%) were included in OC group. 
Table 3. Results of maintenance (by correction angle)

\begin{tabular}{lccc} 
Result & Optimal correction & Under correction & $p$-value \\
Good maintenance & $25(71.4)$ & $6(42.9)$ & $<0.05$ \\
Loss of correction & $10(28.6)$ & $8(57.1)$ & $14(28.6)$ \\
\hline Total $(n=49)$ & $35(71.4)$ & $1 \%$ & \\
\hline
\end{tabular}

Values are presented as number (\%).

Table 4. Results of maintenance (by pelvic incidence)

\begin{tabular}{|c|c|c|c|}
\hline Result & Low PI (22 patients) & High PI (27 patients) & $p$-value \\
\hline OC (35 patients) & & & 0.068 \\
\hline Good (SVA $<5 \mathrm{~cm})$ & $16(84)$ & $9(56)$ & \\
\hline Loss (SVA $\geq 5 \mathrm{~cm})$ & $3(16)$ & $7(44)$ & \\
\hline UC (14 patients) & & & 0.347 \\
\hline Good (SVA<5 cm) & $2(67)$ & $4(36)$ & \\
\hline Loss (SVA $\geq 5 \mathrm{~cm}$ ) & $1(33)$ & $7(64)$ & \\
\hline
\end{tabular}

Values are presented as number (\%).

$\mathrm{PI}$, pelvic incidence; OC, optimal correction; UC, under-correction; SVA, sagittal vertical axis.

Table 5. Clinical results

\begin{tabular}{|c|c|c|c|c|c|c|}
\hline \multirow{2}{*}{ Variable } & \multicolumn{3}{|c|}{ Oswestry disability index } & \multicolumn{3}{|c|}{ Visual analog scale } \\
\hline & Preoperative & Last follow-up & $p$-value & Preoperative & Last follow-up & $p$-value \\
\hline Optimal correction & 73.1 & 24.8 & 0.975 & 8.4 & 3.1 & 0.852 \\
\hline Under correction & 72.1 & 32.7 & & 8.9 & 2.7 & \\
\hline$p$-value & \multicolumn{3}{|c|}{$<0.05$} & \multicolumn{2}{|c|}{$<0.05$} & \\
\hline
\end{tabular}

In OC group, 25 of 35 patients (71.4\%) had good maintenance, whereas in UC group, more than half of the patients had loss of correction (57.1\%) and only 6 of 14 patients $(42.9 \%)$ were within normal range of SVA at the last follow-up $(p<0.05)$. Due to small number of cases, we could not obtain statistical significance in comparisons between low and high PI patients. However, among the patients of OC group (35 patients), low PI group showed a tendency of better results (84\%), as compared to high PI group (56\%) without statistical significance $(p=0.068)$ (Tables 3, 4).

\section{Clinical results}

There was a significant decrease in ODI and VAS of low back pain at the last follow-up, as compared to the preoperative ODI and VAS in both OC and UC groups (Table 5). The mean ODI at the last follow-up of OC group
(24.8 \pm 10.0$)$ was lower than that of UC group (32.7 \pm 10.1$)$, which was not statistically significant $(p=0.975)$. In the same way, the mean VAS at the last follow-up of OC group (3.1 \pm 1.9$)$ was lower than that of UC group (2.7 \pm 1.4$)$ (Table 5).

\section{Complications}

Revision surgery was carried out in cases of surgical complications; 1 case due to pedicle screw malposition and 3 cases due to postoperative neurologic deficit in the lower extremity. Exploration with microscopy was performed in 3 cases with neurologic deterioration and no definite sign of nerve injury was found. Additional decompression and irrigation were conducted. All the patients showed progressive recovery of motor weakness after the revision surgery. 


\section{Discussion}

Understanding the concept of sagittal spinal balance and compensatory mechanism is essential to planning surgical treatment of sagittal spinal deformity. Sagittal imbalance can be caused by decreased LL and increased TK, and can furthermore be influenced by the PI and flexion contracture of the hip and knee joints [3]. Basically, flat back deformity occurs as a result of decrease in LL and thus restoration of LL to the normal state is the main target of surgery. In the past, it was recommended to restore LL to normal range. However, since there is a wide normal range among individuals, some surgeons attempted to correct LL by approximately $20^{\circ}$ more than TK. Kim et al. [20] analyzed postoperative sagittal balance following long adult spinal instrumentation and fusion. They reported that a sagittal Cobb angle difference between LL and TK of $>20^{\circ}$ is advisable to achieve optimal sagittal balance [20]. However, in flat back deformity, it is difficult to determine the accurate amount of correction with the method mentioned above, because TK usually decreases due to the compensatory action, as a result of loss of LL. Moreover, chin-brow vertical angle method is another means of predicting LL. However, it is usually used in gaining horizontal gaze in fixed global deformity such as ankylosing spondyltis, thus it is inappropriate for flexible types.

Recently, numerous studies emphasized the relevance of LL and corresponding influence of pelvic parameters [18,21-23], including pelvic incidence (PI), PT, sacral slope, and overhang (Fig. 1). PI is defined as the angle between the perpendicular line to the sacral end plate at its midpoint and the line connecting this point to the axis of the femoral heads [12]. Among the pelvic parameters, $\mathrm{PI}$ is the most critical factor because it is the only parameter that is unique to each patient and is independent of the position of the pelvis. In present study, preoperative, postoperative, and last follow-up PI of each individual showed no significant difference, suggestive of constant and unique features. Functionally, PI is closely related to optimal LL [23-25]. There have been various attempts to predict LL using pelvic parameters. Legaye et al. [12] measured pelvic parameters in 49 adults free of vertebral disease and demonstrated a predictive equation for lordosis based on the parameters. Moreover, they suggested that a low value of PI implies low values of pelvic parameters and a flattened lordosis, whereas a high value implies well-tilted pelvic orientation and pronounced lordosis [12]. Vialle et al. [13] measured sagittal parameters of 300 asymptomatic volunteers and analyzed the relationships among them to predict maximal LL. Boulay et al. [11] evaluated 149 healthy adults to determine a lordosis predictive equation based on PI. They additionally used T9 tilt to predict LL and claimed that it increased reliability [11]. In 2010, Schwab et al. [15] analyzed radiographic values and ODI of 125 patients with spinal deformity and suggested that realignment objectives should include $\mathrm{SVA}<5 \mathrm{~cm}, \mathrm{PT}<25^{\circ}$, and LL proportional to the $\mathrm{PI}\left(\mathrm{LL}=\mathrm{PI} \pm 9^{\circ}\right)$ [15]. In our study, patients who were under-corrected eventually had more loss of correction at the last follow-up (57.1\%). We focused on the degree of OC of LL to restore normal sagittal alignment. We used Schwab's method $\left(\mathrm{LL}=\mathrm{PI} \pm 9^{\circ}\right)$, which was relatively simple and tried to realign LL proportional to PI for prediction of target LL. Nevertheless, 14 of 49 patients (29\%) were under-corrected (UC group; LL $<\mathrm{PI}-9^{\circ}$ ) on immediate postoperative radiographs. Patients in OC group had significantly better maintenance of sagittal balance (SVA $\leq 5$ $\mathrm{cm})$ with less correction loss at the last follow-up $(p<0.05)$. Thus it is critical to realign LL proportional to PI, within $9^{\circ}$, to get a satisfactory result (Fig. 2).

Each individual has unique size of PI and therefore we hypothesized that if a patient has low PI, it would be easier to get OC since less LL is required to be corrected, resulting in better prognosis. Lee et al. [16] reported that mean value of PI in healthy adults was $52.5^{\circ}$. In addition, Legaye et al. [12] indicated the mean value of PI as $51^{\circ}$. The mean PI of 49 patients included in this study was $55.6^{\circ}$. Therefore, we classified the patients into 2 groupslow PI group $\left(\mathrm{PI}<55^{\circ}\right)$ and high PI group $\left(\mathrm{PI} \geq 55^{\circ}\right)$. The low PI group showed a tendency of better OC (86.4\%), as compared to high PI group (59.3\%) although it was not statistically significant $(p=0.057)$. It means that if a patient has high PI, more LL is required to be corrected in order to make LL proportional to PI, which results in more chances of under-correction and correction loss at the last follow-up. Therefore, we recommend for sufficient LL in relation to PI, and in high PI patients, any type of osteotomy should be performed if optimal LL is not achieved with ALIF (Fig. 3).

ODI improved at the last follow-up, as compared to the preoperative ODI in both OC and UC groups $(p<0.05)$. However the mean ODI at the last follow-up of both groups showed no significant difference $(p=0.975)$. This is 

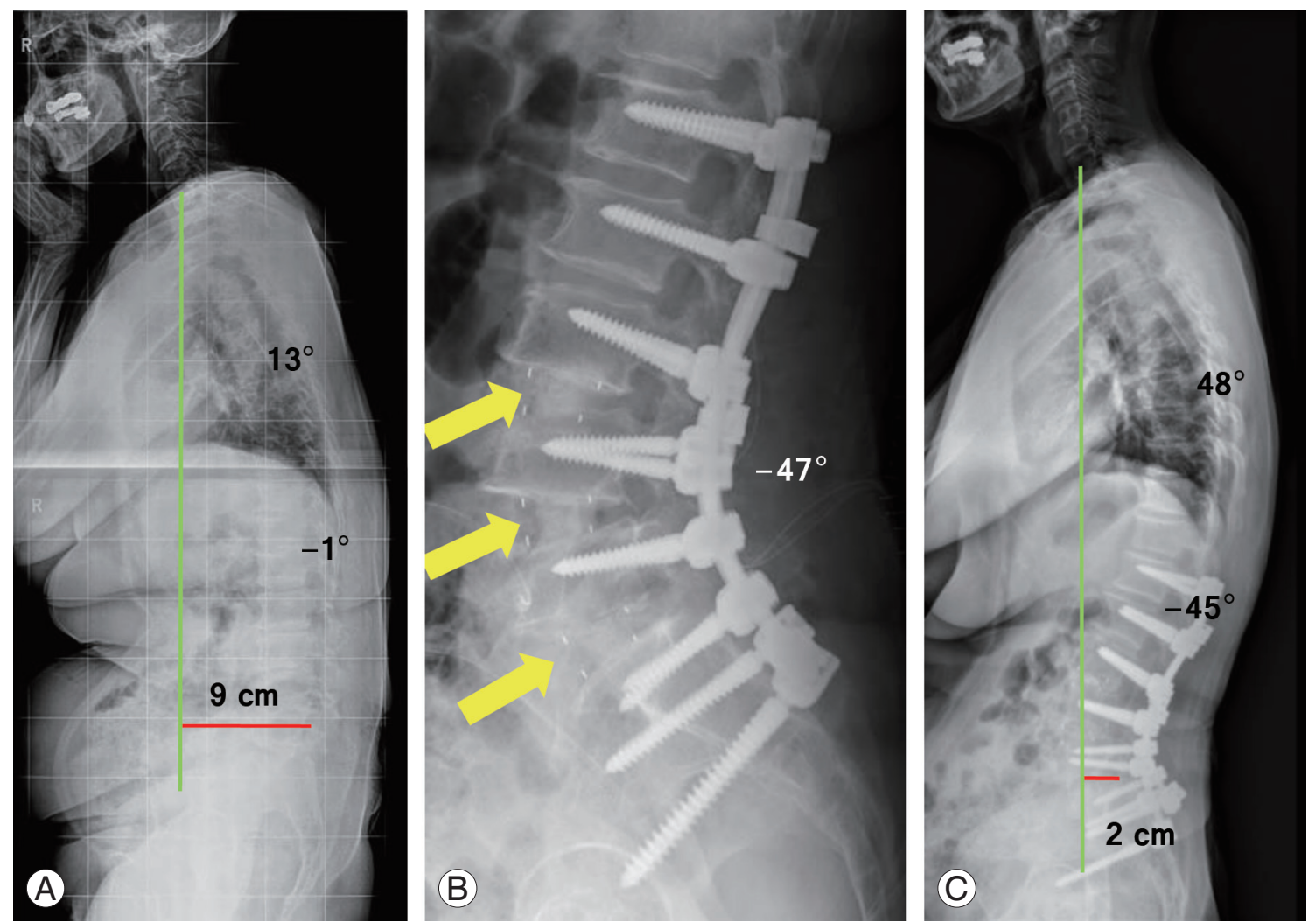

Fig. 2. A 63-year-old female with degenerative flat back (A) received corrective surgery via 2 staged posterior-anterior-posterior approach. The patient had low pelvic incidence (PI) of $46^{\circ}$. Lumbar lordosis was optimally corrected to $47^{\circ}$, which was within $9^{\circ}$ of $\mathrm{PI}(\mathrm{B})$. At last follow-up, correction is well maintained with sagittal vertical axis within normal range $(<5 \mathrm{~cm})(\mathrm{C})$. Arrows, interbody fusion cage.
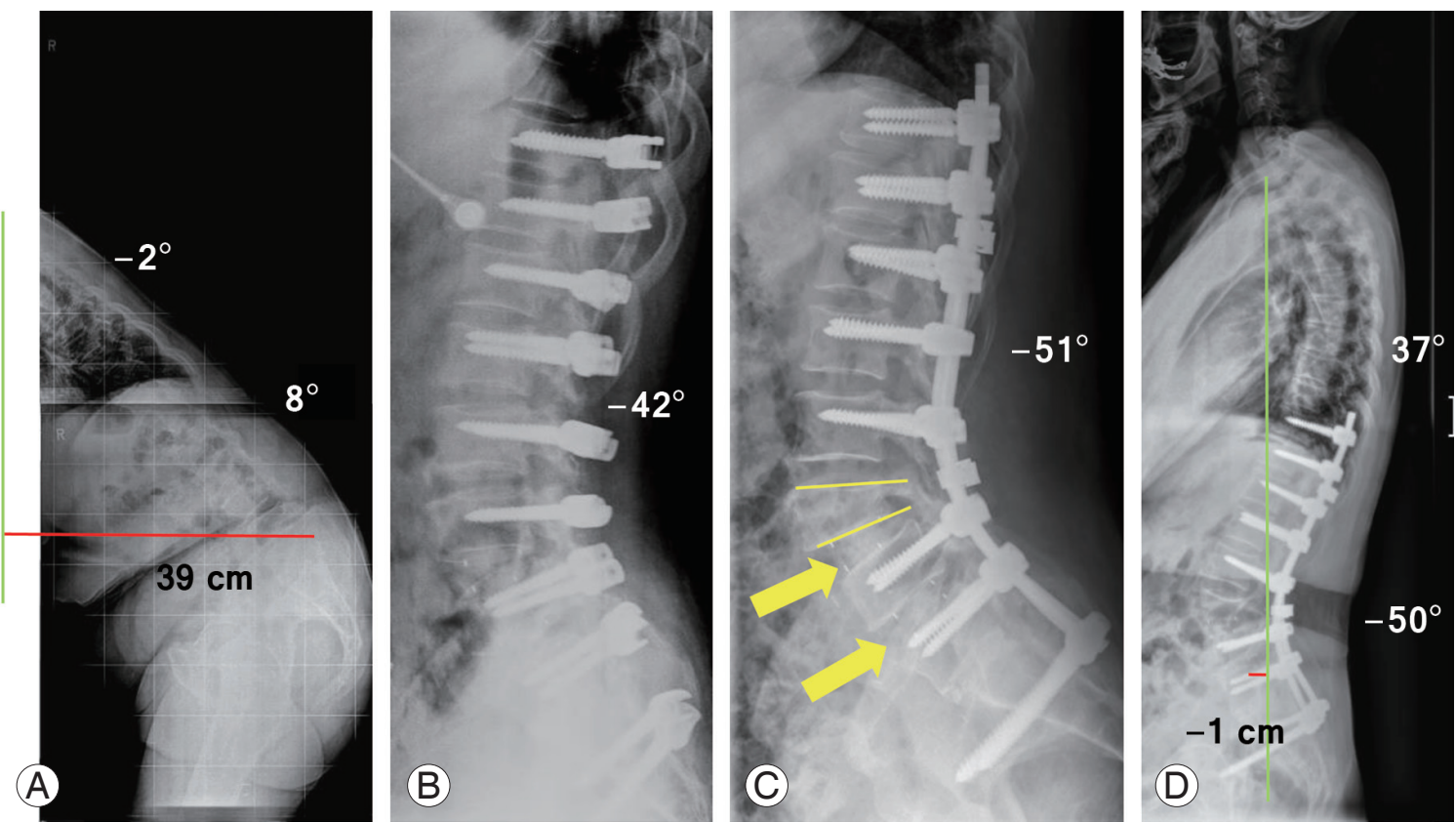

Fig. 3. A 64-year-old female with degenerative flat back showing severe forward inclination of trunk (A). Pelvic incidence (PI) was $58^{\circ}$. After anterior lumbar interbody fusion on L4-L5-S1, lumbar lordosis (LL) increased to $42^{\circ}$ which was not in the target range $\left(\mathrm{LL}=\mathrm{P} \mathrm{I}_{ \pm} 9^{\circ}\right)(\mathrm{B})$. Therefore, we additionally underwent partial pedicle subtraction osteotomy on $\mathrm{L} 4$ and acquired sufficient $\mathrm{LL}$ of $51^{\circ}(\mathrm{C})$. At last follow-up, sagittal balance is well maintained (D). Arrows, interbody fusion cage. 
because ODI not only reflects stooping symptoms due to sagittal imbalance but also reflects back and leg pain and other factors influencing daily living activities.

The limitations of the study were that it was a retrospective study with short follow-up period. Other factors influencing the outcome of surgery (e.g., age, osteoporosis, condition of hip and knee joint) should also be considered. Further study with a higher number of cases and longer follow-up will be needed to confirm our preliminary report.

\section{Conclusions}

Correction of $\mathrm{LL}$ proportional to $\mathrm{PI}\left(\mathrm{LL}=\mathrm{PI} \pm 9^{\circ}\right)$ will result in better sagittal balance with less correction loss in corrective surgery of flat back deformity. Loss of sagittal balance due to insufficient correction may often occur in patients with high PI $\left(\mathrm{PI} \geq 55^{\circ}\right)$. Therefore, care should be taken to obtain sufficient LL proportional to PI.

\section{Conflict of Interest}

No potential conflict of interest relevant to this article was reported.

\section{References}

1. Doherty JH. Complications of fusion in lumbar scoliosis: proceedings of the Scoliosis Research Society. J Bone Joint Surg Am 1973;55:438.

2. Kostuik JP, Maurais GR, Richardson WJ, Okajima Y. Combined single stage anterior and posterior osteotomy for correction of iatrogenic lumbar kyphosis. Spine (Phila Pa 1976) 1988;13:257-66.

3. Kim KT, Lee JH. Sagittal imbalance. J Korean Soc Spine Surg 2009;16:142-51.

4. Bridwell KH, Glassman S, Horton W, et al. Does treatment (nonoperative and operative) improve the two-year quality of life in patients with adult symptomatic lumbar scoliosis: a prospective multicenter evidence-based medicine study. Spine (Phila Pa 1976) 2009;34:2171-8.

5. Farcy JP, Schwab FJ. Management of flatback and related kyphotic decompensation syndromes. Spine (Phila Pa 1976) 1997;22:2452-7.

6. Crandall DG, Revella J. Transforaminal lumbar interbody fusion versus anterior lumbar interbody fusion as an adjunct to posterior instrumented correction of degenerative lumbar scoliosis: three year clinical and radiographic outcomes. Spine (Phila Pa 1976) 2009; 34:2126-33.

7. Pateder DB, Kebaish KM, Cascio BM, Neubaeur P, Matusz DM, Kostuik JP. Posterior only versus combined anterior and posterior approaches to lumbar scoliosis in adults: a radiographic analysis. Spine (Phila Pa 1976) 2007;32:1551-4.

8. Bridwell KH, Lenke LG, Lewis SJ. Treatment of spinal stenosis and fixed sagittal imbalance. Clin Orthop Relat Res 2001;(384):35-44.

9. Lee SH, Kim KT, Suk KS, Lee JH, Seo EM, Huh DS. Sagittal decompensation after corrective osteotomy for lumbar degenerative kyphosis: classification and risk factors. Spine (Phila Pa 1976) 2011;36:E538-44.

10. Lee CS, Chung SS, Kang KC, Park SJ, Shin SK. Normal patterns of sagittal alignment of the spine in young adults radiological analysis in a Korean population. Spine (Phila Pa 1976) 2011;36:E1648-54.

11. Boulay C, Tardieu C, Hecquet J, et al. Sagittal alignment of spine and pelvis regulated by pelvic incidence: standard values and prediction of lordosis. Eur Spine J 2006;15:415-22.

12. Legaye J, Duval-Beaupere G, Hecquet J, Marty C. Pelvic incidence: a fundamental pelvic parameter for three-dimensional regulation of spinal sagittal curves. Eur Spine J 1998;7:99-103.

13. Vialle R, Levassor N, Rillardon L, Templier A, Skalli W, Guigui P. Radiographic analysis of the sagittal alignment and balance of the spine in asymptomatic subjects. J Bone Joint Surg Am 2005;87:260-7.

14. Rose PS, Bridwell KH, Lenke LG, et al. Role of pelvic incidence, thoracic kyphosis, and patient factors on sagittal plane correction following pedicle subtraction osteotomy. Spine (Phila Pa 1976) 2009;34:78591.

15. Schwab F, Patel A, Ungar B, Farcy JP, Lafage V. Adult spinal deformity-postoperative standing imbalance: how much can you tolerate? An overview of key parameters in assessing alignment and planning corrective surgery. Spine (Phila Pa 1976) 2010;35:2224-31.

16. Lee CS, Chung SS, Chung KH, Kim SR. Significance of pelvic incidence in the development of abnormal sagittal alignment. J Korean Orthop Assoc 2006;41: 274-80.

17. Lee CS, Kim YT, Kim E. Clinical study of lumbar 
degenerative kyphosis. J Korean Soc Spine Surg 1997; 4:27-35.

18. Klineberg E, Schwab F, Smith JS, Gupta MC, Lafage V, Bess S. Sagittal spinal pelvic alignment. Neurosurg Clin N Am 2013;24:157-62.

19. Fairbank JC, Pynsent PB. The Oswestry Disability Index. Spine (Phila Pa 1976) 2000;25:2940-52.

20. Kim YJ, Bridwell KH, Lenke LG, Rhim S, Cheh G. An analysis of sagittal spinal alignment following long adult lumbar instrumentation and fusion to L5 or S1: can we predict ideal lumbar lordosis? Spine (Phila Pa 1976) 2006;31:2343-52.

21. Labelle H, Roussouly P, Berthonnaud E, Dimnet J, O'Brien M. The importance of spino-pelvic balance in L5-s1 developmental spondylolisthesis: a review of pertinent radiologic measurements. Spine (Phila Pa
1976) 2005;30:S27-34.

22. Legaye J, Duval-Beaupere G. Sagittal plane alignment of the spine and gravity: a radiological and clinical evaluation. Acta Orthop Belg 2005;71:213-20.

23. Roussouly P, Gollogly S, Berthonnaud E, Dimnet J. Classification of the normal variation in the sagittal alignment of the human lumbar spine and pelvis in the standing position. Spine (Phila Pa 1976) 2005;30: 346-53.

24. Wollowick AL, Glassman SD, Perra JH, Schwab FJ. Patient evaluation and clinical assessment of adult spinal deformity. Instr Course Lect 2012;61:469-79.

25. Berthonnaud E, Dimnet J, Roussouly P, Labelle H. Analysis of the sagittal balance of the spine and pelvis using shape and orientation parameters. J Spinal Disord Tech 2005;18:40-7. 